\title{
Research on public perception and participation in the relic park__taking Zhengzhou Shang Dynasty city wall relic park as example
}

\author{
Zhengwang, $\mathrm{Wu}^{1, *}$, and Jingyi, $\mathrm{Ye}^{1}$ \\ ${ }^{1}$ School of Architecture, Huaqiao University, Xiamen, Fujian Province, 361021, China
}

\begin{abstract}
The city wall relic park in Zhengzhou is a city park built on the Shang Dynasty city Wall site. As Zhengzhou is chosen as the eighth ancient capital of China, it is gradually recognized by the public. However, due to the lack of protection, development and utilization of the site, the historical value and cultural value of the Shang Dynasty Wall in Zhengzhou have not been fully shown. The construction of the city wall relic park is related to the soft inheritance and protection of the historical heritage. The spiritual inheritance of the historical heritage mainly depends on the spiritual transmission of the public. The public has the most direct feeling and understanding of it, so it is necessary to introduce public participation. In this paper, the scientific evaluation method Post Occupancy Evaluation (POE) is used to discuss the problem found by the public when using the city wall space. Suggestions and public participation strategies are given on the construction of the city wall relic park. We need to think about if there is public participation in the site now and how to let the public participate in planning, construction and management of the relic park. In order to make the city wall become the city's leisure living room, to build the brand of Zhengzhou, and make it famous across the whole country, it's urgent to put forward countermeasures for the development problem of Zhengzhou.
\end{abstract}

\section{Foreword}

The city wall of the Shang Dynasty of Zhengzhou has a shape of rectangle with a history of more than 3500 years. The north wall is about $1704 \mathrm{~m}$ long, the east wall is about $1716 \mathrm{~m}$ long, the south wall is about $1721 \mathrm{~m}$ long, the west wall is about $1859 \mathrm{~m}$ long, and the circumference is nearly $7 \mathrm{~km}$. The urban area is about 3.3 $\mathrm{km}^{2[1]}$. The City Wall Relic Park is built on the southeast part of relic city wall, which is the most complete remaining part of the site.

Shang Dynasty city wall relic park is located in the southeast corner of the city wall between West Street and Southern City Road. Its planning concept is to extend the display of the city wall relics to the display of Shang Dynasty culture, to provide residents with colorful activity spaces, at the same time, to create a functional space with urban characteristics of Zhengzhou. The study area is located in the relic park, and the research objects mainly include the activists in the park and the ones on the city walls.

Post Occupancy Evaluation ${ }^{[2,3]}$ (POE) is an analysis of the degree to which the environment meets the needs of current users after completion. After field investigation and analysis, an objective scientific conclusion is drawn. Based on the POE research method, this article makes a scientific and objective evaluation of the current construction of the Shang Dynasty Relic Park, and then applies the conclusions of the evaluation directly to the management and latter construction of the Shang Dynasty Relic Park, and makes targeted improvements. I hope that from the perspective of the public, I will discover some potential problems and listen to the public's voice for new needs, learn the current status of residents' participation in the planning, construction, protection, and management of the relic park, and explore the practice of public participation in the later stage of the relic city park. 


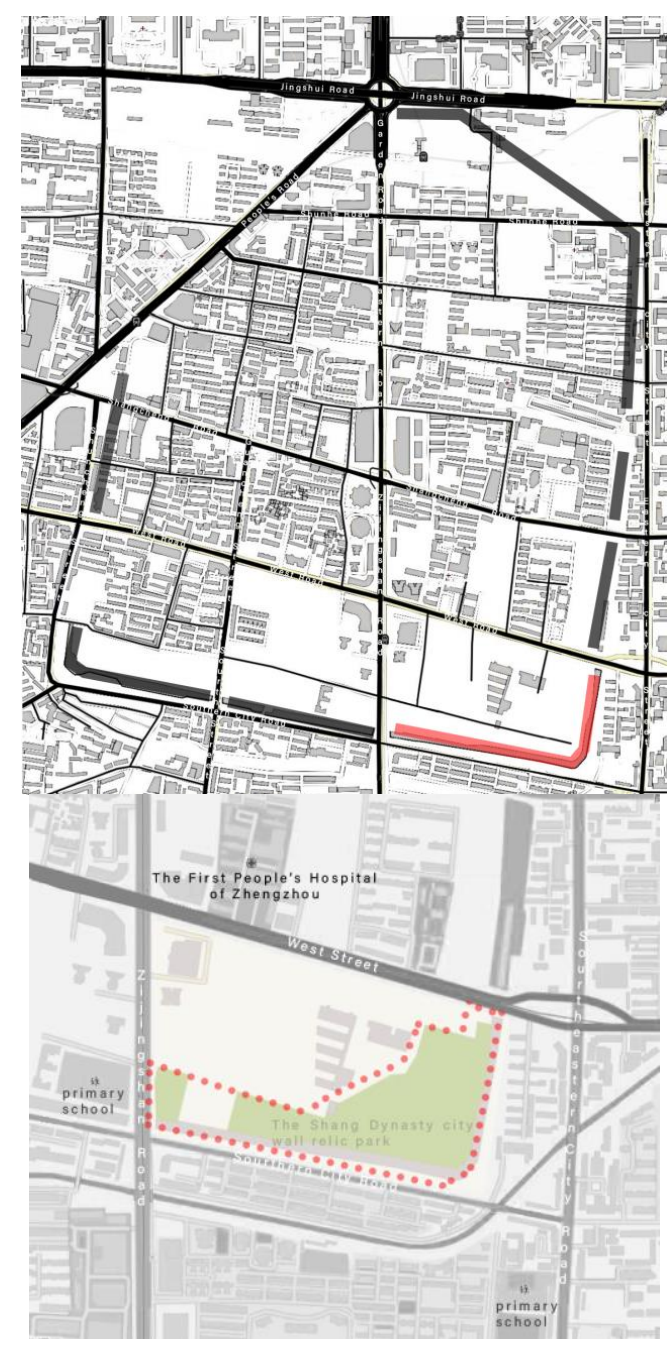

Fig. 1. a. Distribution of existing city walls. b. Research range

\section{Status evaluation of the city wall relic park}

\subsection{Research Objects of the City Wall Relics Park}

Nearly the 200-meter-long northern part of the eastern city wall uses a modern rammed earth technology as the restoration method. The city walls have sharp and angular edges, as it is shown in Figure 2.

The southern part of the eastern wall and the southern wall of the relic park are protected by soil cover, as it shown in Figure 3. A layer of rammed earth was applied above the city wall through a layer of air, and herbaceous plants were planted on the rammed earth surface, where green space was introduced while, protecting the city wall. The original Chinese scholar tree on the city wall was preserved, and the soil layer was located in the middle level of the original Chinese scholar tree.

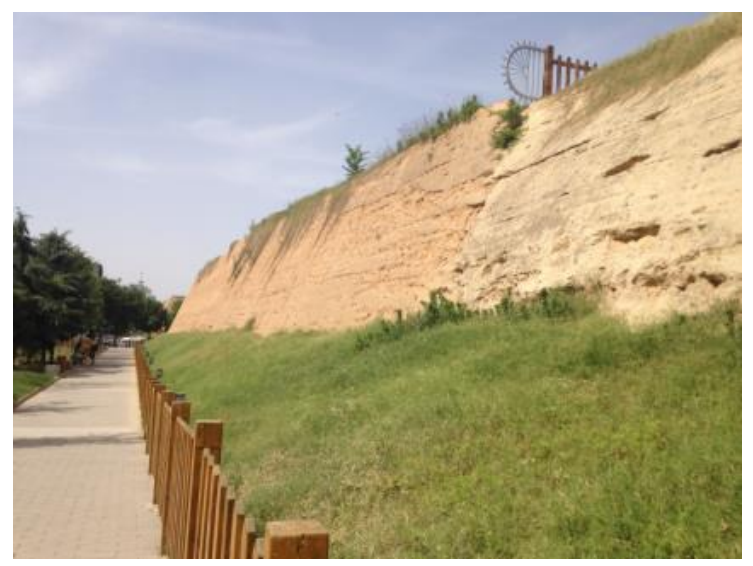

Fig. 2. The northern part of the eastern city wall is displayed using the restoration method.

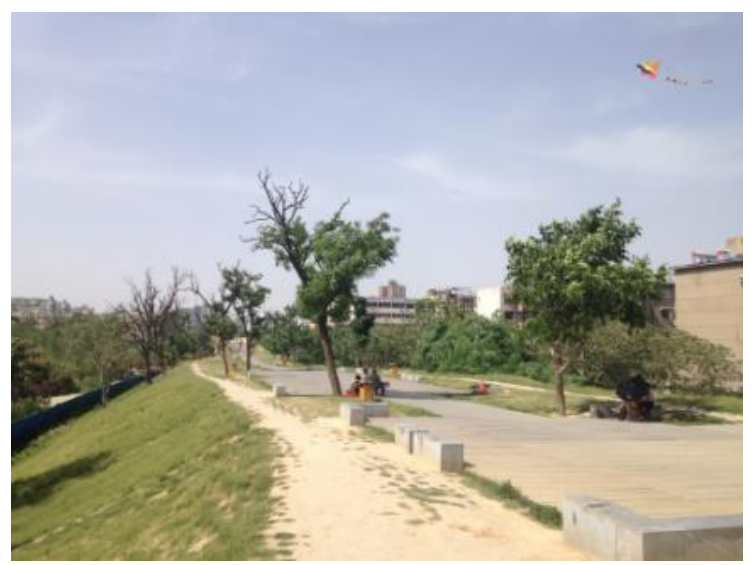

Fig. 3. The southern part of the eastern city wall and the southern part of the relic park are protected by covering with soil

The street corner space and the relic park are distributed with green space, activity squares, fitness grounds, children's bunkers, corridors and pavilions, which meet the surrounding residents' needs of daily leisure activities, but the instinct feeling is that the characteristics of the city wall relic and surroundings are not connected. The cultural and archaeological value of the city wall relic and surroundings are not connected. Hence the city wall relic has given a favorable support to Zhengzhou in order to increase the value of the city to become one of the 'eight ancient capitals of China'. Although the city wall relic park has become the performance stage of urban civilization landmarks, the influence of the current city wall relic is very limited and much work remains unfinished.

\subsection{Research method}

The survey was conducted in a closed questionnaire survey. A total of 90 questionnaires were distributed and 82 were recovered with a recovery rate of $91.1 \%$. From investigating the park 's users, the main users of the city wall relic park are local citizens, and residents in both nearby areas and other districts in Zhengzhou which is as high as $95 \%$ of the respondents, indicating that the current Shang Dynasty city wall relic park is more popular among local citizens, and it has become a public 
recreation center for citizens, a place for leisure and entertainment, but its range of influence is limited to Zhengzhou City, as it shown in Fig. 4. The relic park's attraction to tourists is extremely limited, which also shows that the park has a very large potential. This study uses both, the real-time observation and a behavior map method to study whether there is public participation and how to promote participation in the planning, construction and management of Zhengzhou Shang Dynasty city wall relic Park. In order to come up with countermeasures to make the Shang Dynasty city wall Relic Park an urban lounge and living room, build Zhengzhou's brand image, and raise its national popularity, which is an urgent need to be solved in the development of Zhengzhou.

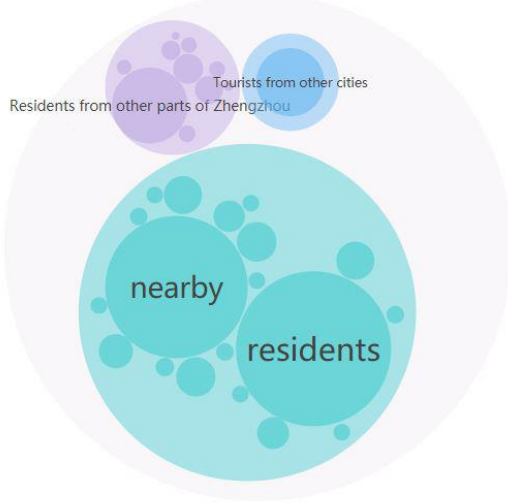

Fig. 4. The source of the visitors

\subsection{Research content}

There are more male users than female users in the Shang Dynasty Relic Park. The two account for $62 \%$ and $38 \%$ of the total respectively. Men are more willing to take walks and do exercise in the park; The number of young and middle-aged users between the ages of 26 and 40 is most at $43 \%$, followed by middle-aged and older people from 41 to 60 years old, accounting for $33 \%$ of the total number. Among the randomly selected samples, the number of users younger than 16 years old is very small, only 4 people, which gives us only $5 \%$. It can be seen from the above data that Shang Dynasty relic park is suitable for all ages.

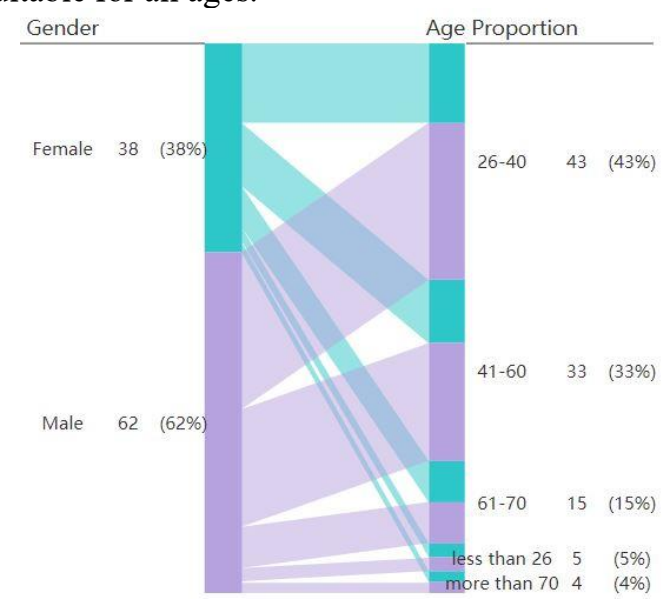

Fig. 5. Visitor's age and gender diagram
$55 \%$ of park users live a distance of less than $1000 \mathrm{~m}$ from the park, $24 \%$ of the users live 1000-3000m away, and long-distance tourists with a distance of more than $3000 \mathrm{~m}$ account for $21 \%$ of the respondents. From this data, we can know that the most users of the relic park are in the close proximity.

In terms of users' transportation methods, the vast majority are on foot or by bus, up to $78 \%$ of the total, but there are fewer residents and tourists who choose to drive from a longer distance to come here by themselves, which indicates that at present although the residents in the neighborhood have fully enjoyed the park resources, the influence of the city wall relic park is still limited to the surrounding areas.

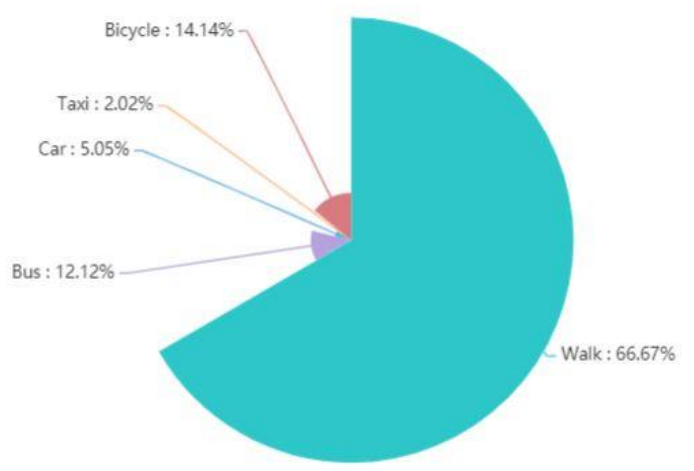

Fig. 6. Users' transportation methods

The current function of the park is limited to a recreational park with a radius of $3000 \mathrm{~m}$ in the city center. The advantages of relying on the ruins of Shang Dynasty city wall have not been well utilized. The promotion of the city wall relic and the Shang Dynasty culture needs further attention.

Judging from the purpose of users coming to the park, the majority of people who come here for walking, doing sports and fitness, accounts for $71 \%$ of the total number of respondents, indicating that the environment here is good. Only $24 \%$ of those who come here would like to feel the charm of the ancient city wall, which shows that the relic park mostly plays the role of the central city park, and the charm of the Shang Dynasty relic has not been significantly increased because of the construction of the relic park.

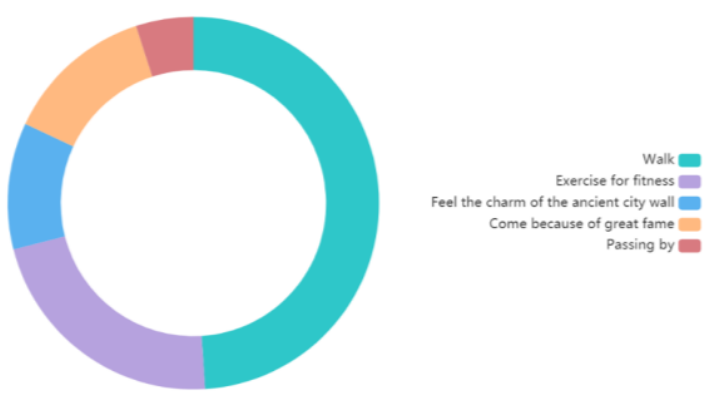

Fig. 7. The purpose of users coming to the park 


\section{Post occupancy evaluation of the Shang Dynasty city wall relic park}

\subsection{Evaluation of space usage}

\subsubsection{Real observation ${ }^{[4]}$}

The upper part of the city wall is linear space. The wooden boardwalks are distributed along the city wall, and there are rest facilities along the wooden walkway. It provides users with a place to walk and relax. The turf growing on the city wall improves the aesthetics; The circular square on the street corner provides an abundant potential of activities; the occupancy of activities on the boardwalk changes with time. When there are many people walking, the flow is strong; when there are few people, there are more activities like stopping and flying a kite.

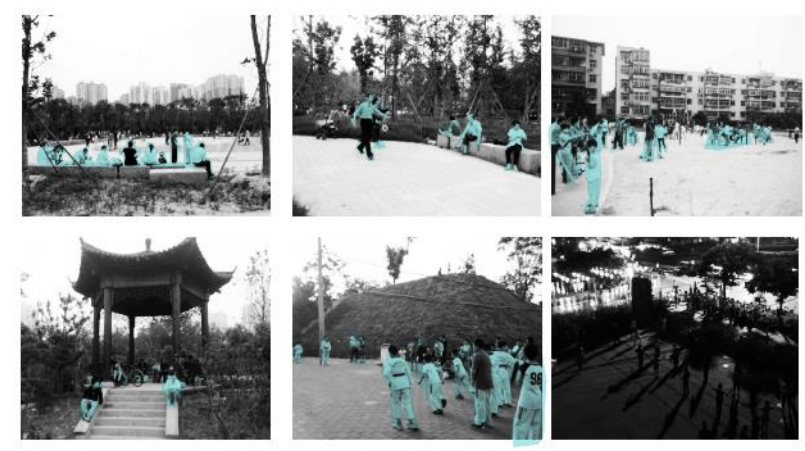

Fig. 8. Analysis of park activity types

There are various types of activities in the park. Resting facilities are arranged at the edges of the squares. Recreation and fitness activities are located inside the square. There are healthy walkways at the edges of the park, which are made for walking and jogging activities. Activities such as rest, reading, talking, etc. are distributed at the side seats, which are rich in activities and full of vitality. The use is different in different season. In spring, there are more kites flying on the city wall; in summer, the sophora trees form shade on the city wall, which makes it more common to take a walk on the wall.

\subsubsection{Behavior map}

Observe and record the behavior map of the Shang Dynasty wall relic park. Select three periods: 7:00 am to 8:00 am, 15:00 pm to $16: 00 \mathrm{pm}$, and 18:00 pm to 19:00 pm to draw the behavior map Fig.9. The behavior map analysis table is shown in Table 1.

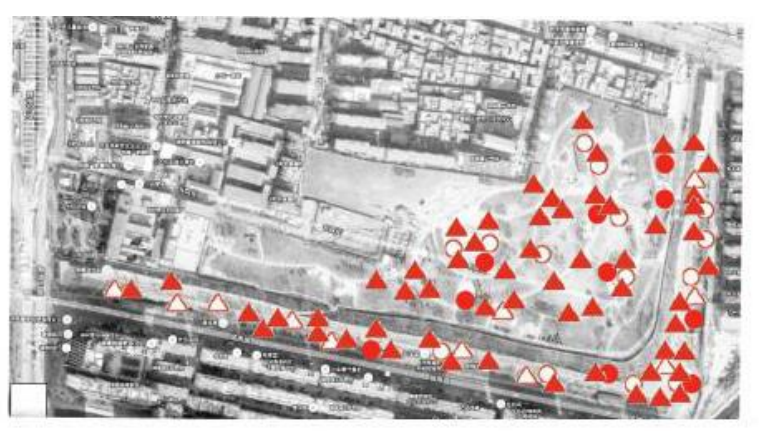

$\Delta \begin{gathered}\text { walking. } \\ \text { exercise }\end{gathered}$ sit $\bigcirc$ entertoinment $\Delta$ poss by
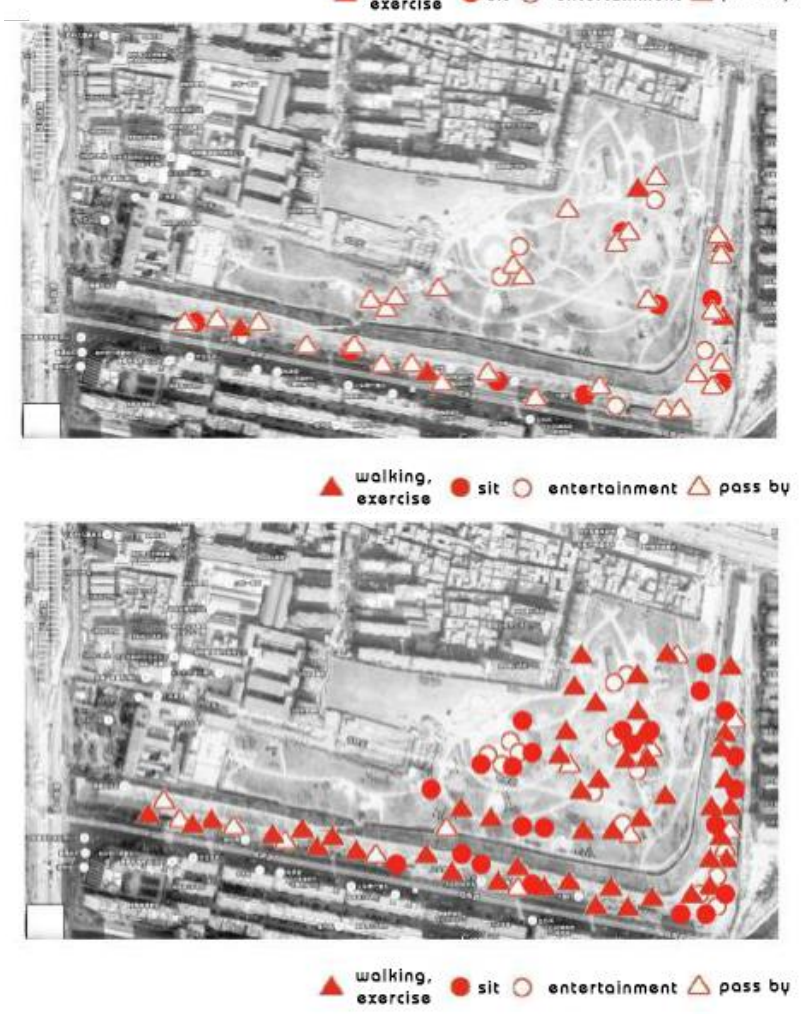

Fig. 9. a, b, c 7:00-8:00 am, 15:00-16:00 pm, and 18:00-19:00 pm behavior map of the city wall relic park

From the behavior map and behavior map analysis table, it can be concluded that the park is popular among older people, at noon, the majority is young people, and people of all ages are more balanced at night. The main types of activities include morning jogging, walking, fitness, tai chi, dance, kite flying, sitting, enjoying the scenery, sitting, etc. In the analysis of space usage, the types of activities in the park are diverse, the activity space is more dynamic, and it can accommodate multiple types of activities.

\subsection{Usage Satisfaction Evaluation of City Wall Relic Park}

In this study, a Likert's scale method ${ }^{[5]}$ is used to design a satisfaction survey questionnaire, and the evaluation 
Table 1. Shang Dynasty city wall relic park behavior map analysis table.

\begin{tabular}{|c|c|c|c|c|c|}
\hline Period & $\begin{array}{l}\text { Microclim } \\
\text { ate }\end{array}$ & $\begin{array}{c}\text { Crowd } \\
\text { characteristics }\end{array}$ & $\begin{array}{c}\text { Main activity } \\
\text { type }\end{array}$ & Activity type distribution & Activity frequency \\
\hline 7:00-8:00 & $\begin{array}{l}\text { Sunny, light } \\
\text { breeze, low } \\
\text { temperature }\end{array}$ & $\begin{array}{c}\text { Mostly older } \\
\text { people, followed } \\
\text { by middle-aged }\end{array}$ & $\begin{array}{l}\text { Morning run, } \\
\text { walking, } \\
\text { fitness, tai chi, } \\
\text { dance }\end{array}$ & $\begin{array}{l}\text { Tai Chi and seniors' dancing are mainly } \\
\text { distributed in the square of the park. A } \\
\text { small number of people are distributed in } \\
\text { the circular square at the corner of the city } \\
\text { wall. Sports such as morning jogging and } \\
\text { race walking are carried out along the } \\
\text { wooden boardwalk on the wall and the } \\
\text { edge of the park. }\end{array}$ & $\begin{array}{l}\text { There are many concentrated } \\
\text { crowds of activities, and the } \\
\text { number of people who jog } \\
\text { and exercise is relatively } \\
\text { large. }\end{array}$ \\
\hline 15:00-16:00 & $\begin{array}{l}\text { Sunny, light } \\
\text { breeze, high } \\
\text { temperature }\end{array}$ & $\begin{array}{l}\text { The number of } \\
\text { middle-aged } \\
\text { people is } \\
\text { increasing, the } \\
\text { number of older } \\
\text { people is } \\
\text { decreasing, and } \\
\text { the number of } \\
\text { young people is } \\
\text { increasing }\end{array}$ & $\begin{array}{l}\text { Kite flying, } \\
\text { sitting and } \\
\text { enjoying the } \\
\text { scenery }\end{array}$ & $\begin{array}{l}\text { A small amount of resting is distributed } \\
\text { under the pavilions and pergola in the park. } \\
\text { Kite flying is distributed on the city walls } \\
\text { and open spaces. Skating is distributed on } \\
\text { the open spaces }\end{array}$ & $\begin{array}{l}\text { The overall flow of people } \\
\text { in the park and on the city } \\
\text { walls is small, and there are } \\
\text { fewer people walking for } \\
\text { leisure.No amusement } \\
\text { crowd, most people in the } \\
\text { park just pass by }\end{array}$ \\
\hline 18:00-19:00 & $\begin{array}{l}\text { It's sunny } \\
\text { and tend to } \\
\text { cool down }\end{array}$ & $\begin{array}{l}\text { People from all } \\
\text { ages are more } \\
\text { than daytime }\end{array}$ & $\begin{array}{l}\text { Walking, } \\
\text { fitness, sitting, } \\
\text { entertainment }\end{array}$ & $\begin{array}{c}\text { Singing and entertainment are distributed } \\
\text { under the pergola, and the sitting rest are } \\
\text { distributed among the stone seats, park } \\
\text { benches, pavilions and pergola along the } \\
\text { wooden boardwalk of the city wall, and } \\
\text { slowly walk is distributed along the park's } \\
\text { healthy walkway and on city wall } \\
\text { boardwalk }\end{array}$ & $\begin{array}{l}\text { Walking and sports have a } \\
\text { large flow of people, and } \\
\text { they are uninterrupted on the } \\
\text { city wall.The sitting crowd } \\
\text { is more homogeneous and } \\
\text { there are more concentrated } \\
\text { active people }\end{array}$ \\
\hline
\end{tabular}

levels are divided into 6 levels - unclear (not superimposed), very poor (1 point), poor (2 points), average (3 points), good (4 points) and very good (5 points). These levels represent the subjective intentions of the evaluator. The evaluation scores of each item are added up and averaged. The evaluation marks each item, which are summed up and averaged. These are shown in Table 2.

The POE impact factors of the Shang Dynasty City Wall Relic Park include the physical environment, social culture, and users. Therefore, the design of the questionnaire mainly considers three factors, namely natural environment factors, artificial facilities factors, and historical cultural factors. On this basis, the issues that the citizens were particularly concerned about during the interview were detailed, and the second-level evaluation index items were set. According to previous free interviews and observations, people are mainly concerned about the natural scenery of the city wall relic park, the convenience of artificial facilities, the comfort of usage, and the cultural atmosphere of the park given by the city wall ruins and historical culture. In this way, the evaluation index system of the city wall relic park is established.

\subsubsection{Natural environment factors}

The green impression score is higher, at 4.043 points, indicating that citizens have a higher overall aweraness of the park's greening, but they think that the diversity of the plants inside the park is not enough, the species is relatively singular, and the score is only 3.511 , which is lower than the total average score. In the free interview, some residents disputed the practice of retaining Chinese scholar trees on the city walls. The survey showed that the residents agreed with current approach with a score of 3.909 .

\subsubsection{Artificial facilities factors}

The wooden broadwalk on the city wall scored the highest, at 4.128 , and the scores of the city wall steps and signposts are also high, at 3.915, indicating that the residents are satisfied and feel comfortable with the wooden paved planks on the city walls, the wooden steps and signpost indication systems connected to the wooden broadwalk. The scores for the bin, toilet and other facilities are 3.787, indicating that most people are having a positive view about it. However, the facilities maintenance and sanitation scores are low at 3.587, which is lower than the average score, indicating that after the construction of the park, the facilities maintenance is not meeting a certain standard. The lighting facilities scored the lowest, only 3.158, indicating that the lighting situation in the park is lacking, which has affected the citizens' normal activities in the park at night, which needs to be improved.

\subsubsection{Historical cultural factors}

The scores of historical and cultural elements are all low, far from the expectations of citizens. The score of the historical and cultural landscape is only 3.085. Except for the three archeologists' bronze sculptures in the park, there are very few other cultural landscapes, and there is almost no connection with the history of the Shang 
Dynasty. The history display of the Shang Dynasty has the lowest score of this item which is only 3.178. And the lack of the theme of the park is also the evaluation of many interviewees in the interview.

Since the park was built on the ruins of the city wall, the introduction to the ruins and protection methods of the city wall should be an important function of the park, but the citizens give only 3.340 marks on the introduction of the site and protection. The benefits of the park building on the ruins of the city wall is not used well. The rammed earth technology of the city wall and the 3,000-year historical vicissitudes of the city wall itself are cultural resources with historical value, which are worthy of good display. However, in the park, there is no special display on the introduction of the technology and historical trace of the city wall, and the city wall display item only got 3.391 .

Cultural activities related to the Shang Dynasty city wall can enhance residents' perception of the park's historical atmosphere, but nevertheless the type of cultural activities has the lowest score, only 3.045, indicating that related cultural activities have not been well carried out in the park. According to the investigation, it is known that although there are occasional events held by the relic protection office of the Shang Dynasty City Wall, in the terms of an ontological property of the relic park, a comprehensive and effective display and interpretation of the relic is still missing.

Above all, the evaluation of natural landscape and artificial facilities are comparatively good, but the facility maintenance and cleaness are relatively low, which requires special attention. Most interviewees had a very low rating of historical and cultural elements, and the historical and cultural attributes of the park did not perform well. Not enough attention was paid to the presentation of the city wall relic itself and the introduction of the relic protection project, and the park's display function was not well reflected. Cultural activities related to relic are a 'soft' way to increase influence, but residents' ratings are low.

Table 2. Satisfaction evaluation index score table and line chart.

\begin{tabular}{cc}
\hline Evaluation item & Average value \\
\hline Green impression & 4.043 \\
Vegetation richness & 3.511 \\
Status after city wall protection & 3.787 \\
Ways of retaining Chinese scholar & 3.909 \\
trees & 3.787 \\
Rest facilities & 3.787 \\
Trash cans and toilets & 3.158 \\
Lighting facilities & 3.915 \\
Road sign indicator & 3.915 \\
steps on the city wall & 4.128 \\
Wooden boardway on city wall & 3.587 \\
Facility maintenance and cleaness & 3.34
\end{tabular}

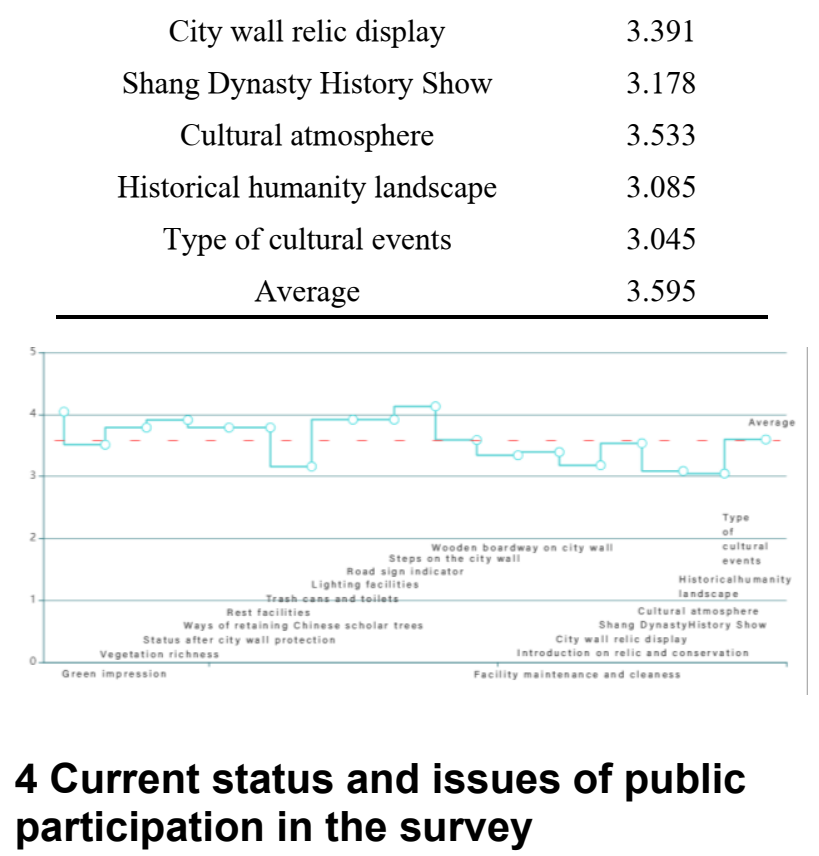

In the previous survey, we found that many people had the willingness to express their opinions and suggestions during our interviews and surveys. We heard a lot of valuable opinions and suggestions. Some citizens pointed out that the positioning and theme of the park are not clear enough, and others have said that 'the pride of the city wall should be stimulated and resonated, so as to elicit the masses' spontaneity. It can be seen that the opinions of masses are of great value and significance, so what is the current status of public participation in the Shang Dynasty city wall relic park? Can ordinary citizens be involved as a force in the heritage protection and park construction?

The survey found that some interviewees were unaware of the relic construction project itself and the related construction status of the park. For example, some citizens did not understand the specific methods of the city wall's protection project, and some even had a large misunderstanding. In the specific interviews, some citizens thought that the method of covering the city wall with soil was a big damage to the original city wall. Some people thought that the restoration of the city wall on both sides of the East Street was a fake, and some even called it 'two coffins'. This also reflects that the definite propaganda of the protection project is not adequate. If there is a good communication between the residents and the city wall management department, this negative misunderstanding can be avoided.

\subsection{Current Status of Public Participation in Shang Dynasty Relic Park}

In the survey, $81 \%$ of the public had a clear sense of participation, that is to say, citizens not only have the right to use but also have the right to make suggestions. This is also the next step for the public to devote great enthusiasm to the various process of the protection. Prerequisites for the process. When relevant departments make decisions, they pay more attention to the overall 
situation, although the public is the exact users of the park. They can find more details about life, and valuing their opinions can ensure that the relevant departments will not neglect the details when making decisions and reduce mistakes.

In the survey of whether they are willing to exchange opinions with the government or city planners, $56 \%$ of people showed a strong willingness to participate, and $35 \%$ has neutral attitude, want to wait and see, and do not reject communication. This shows that these people have a certain sense of participation, but they do not have the willingness to actively participate. Active and potential participants accounted for as much as $91 \%$ of the total investigators, which shows that it is feasible to introduce public participation in the protection of the Shang Dynasty city wall ruins.

The survey showed that $22 \%$ of the citizens who participated in the survey have participated in the public opinion collection process of the relic park, of which only $4 \%$ participated regularly. Non-participation masses accounted for $78 \%$ of the total number. According to the previous analysis, we can see that the public has a willingness to participate, but the proportion of genuine participation is very low. It can be seen that relevant departments have not carried out large-scale publicity, solicited social opinions or expanded discussion.

The answer to 'what do you think hinders your participation' is shown in Figure 10. Respondents who said they didn't know because of the 'insufficiently promotion' had the highest percentage, accounting for $54 \%$, and $25 \%$ chose 'lack of effective channels', so citizens could not participate. It can be seen that relevant government departments should optimize the channels of dialogue and should widely publicize when seeking for the public opinion.

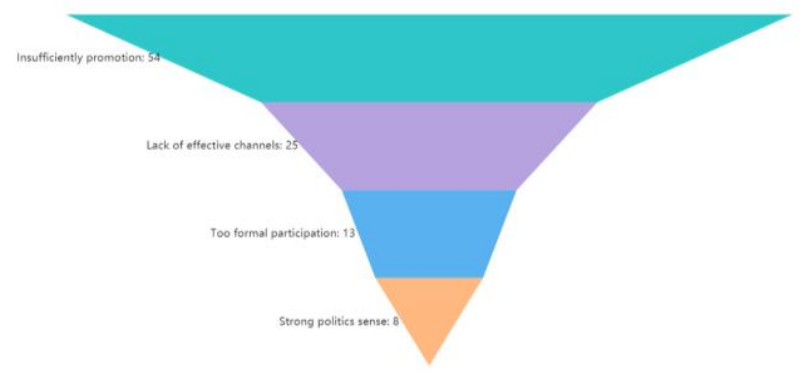

Fig. 10. What hinders Participation?

After understanding the status of participation, we conducted a further investigation of residents' intentions to participate. When being asked what areas they would like to participate in, the results of 'participation in supervision', 'participation in protection' and 'participation in planning' were $35.4 \%, 33.9 \%$, and $14.2 \%$, which are shown in Fig. 11 . indicating that it is possible to consider expanding the range of participation and introducing public participation to all stages.

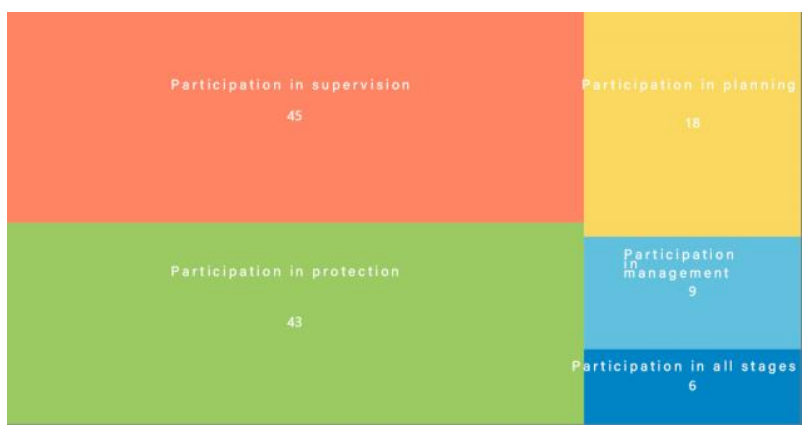

Fig. 11. Distribution of wanting to participate in which fields

How the respondents want to get the information of the relic park are shown in Figs. 12 and 28\% people chose to understand the information through social activities, $24 \%$ chose to participate online, and $22 \%$ and $13 \%$ participated through television and paper media. $11.9 \%$ learned through government notices, and 13\% learned and participated through mobile phone text messages. It is necessary to enrich and expand the channels of participation to meet the needs of public participation at this stage.

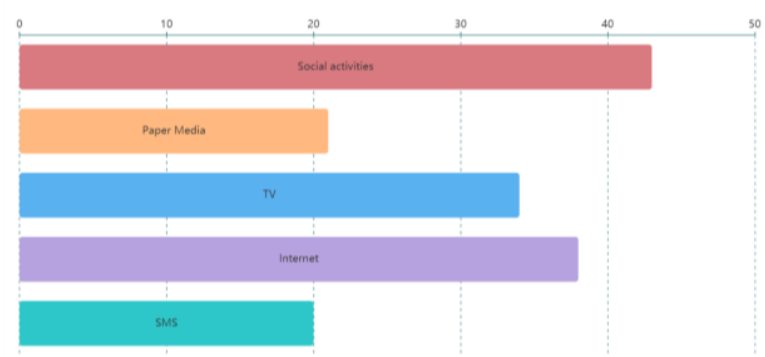

Fig. 12. How to get the information of the relic park

\subsection{Analysis of obstacles to public participation in Shang Dynasty City Wall Park}

According to the survey and analysis of the participation status, most people have a sense of participation, but the public participation in every stage of planning and construction in Shang Dynasty relic park is generally inadequate, and there is a lack of interaction between relevant management departments and the public. The reasons leading to the current lack of participation are below:

The government did not organize participation- the government is the leader in the preparation and implementation of the planning, but has not solicited public opinion, and the relevant departments have not publicly publicized the discussions related to the site planning. The public is unaware of the work done by government departments, and if individuals have opinions and ideas, they can only discuss in private. After it was put into use, government departments were so proud that they even ignored public opinion. Throughout the planning, reconstruction, and management of the relic park, the public as the park's service target has almost no room for participation.

Insufficient participation ways - In the survey on the status of participation, most respondents believe that the 
lack of effective participation ways are an important reason affecting their participation. They do not know any procedure from the park's planning to the completion of construction, and they are not clear about the operations and activities of the park management department. There are no communication opportunities between the government, experts, and the public. The government does not actively establish participation possibilities. There is no community to organize the public to participate in supervision and management. Effective communication and cooperation between two or more parties have not been achieved.

Information publicity is lagging - some interviewees stated in the interview that before the construction of the park, the plan was displayed with a display board near the city wall. After the plan is determined, the public display is only an exhibition of the established results. It seems that the information has been made public, but the residents 'ideas and suggestions will no longer have an impact. In addition, the relevant departments have not done any communication and inquiry work with the public, in other words, public participation just stays in form.

Lack of feedback mechanism - Some interviewees said that someone had written a letter of comments to the relevant department, but never received a response. After the active participation of the public without timely response, people have to give up. The enthusiasm for public participation has been thwarted and the desire to participate has diminished.

\section{Public participation strategy of the Shang Dynasty city wall relic and suggestions for the later construction of the park}

\subsection{Public participation strategy}

Expanding the range of participation - the construction of the relic park is closely related to the public life, and the park's service target is the public. The public have the right to know, participate and speak on each stage of the planning and construction, and can cooperate with different authorities to make their own voices in various ways. For example, in the planning stage, the public lack of professional knowledge and cannot be the subject of participation, but can express their own ideas and discuss with experts and decision makers. After the implementation of the plan, the public can play the role of supervisor, supervising the implementation of the plan and the construction of the park. Referring to the Japanese community construction case, and non-profit community groups can gather public opinions and then communicate with government departments.

Rich ways of participation - rich forms of activities can stimulate the public's enthusiasm for participation. The ancient city wall photography competition, Shang Dynasty history knowledge competition, and historical performance mentioned in the questionnaire have been favored by the respondents. The pie chart distribution is shown in the figure 10 . Among them, $33 \%$ chose the historical performance, $26 \%$ chose the historical knowledge contest, $18 \%$ chose the ancient city photography competition, and $16 \%$ people chose the opera.

The fun and experience of the event can attract public participation and greatly mobilize people's enthusiasm for participation. As mentioned above, the ancient city wall photography competition, Shang Dynasty city historical knowledge competition, and historical situation performance can all attract public participation through the fun and experience of the event. Besides, we need to pay attention to the differences in material and spiritual needs of different groups, and design different activities for residents of different ages, education levels and economic incomes.

Improve the information publicity system Information disclosure should be reliable, truthful, and timely. Remind the public what issues they can focus on at this stage, what they can do and how. The possible negative effects of planning projects should also be outspoken, not hidden, and problems such as obscure technical terms should be avoided. Information can be publicly released in the form of on-site publicity, mass media, and Internet television. At the same time, relying on the media's supervisory role will also increase the effectiveness of feedback. Newspapers and magazines have the features of wide audience, fast speed, while internet platforms have better timeliness and interaction. Various feedback mechanisms can be combined to ensure the openness, timeliness, and transparency of the government-public communication platform.

Improve the information feedback system - in order for the public to effectively communicate and cooperate with the government or experts, it is necessary to enrich the methods of participation to meet the needs of different stages. Interactive communication can achieve the goal of good communication between the government and citizens. The government should actively and promptly respond to public opinion and respond to focused hot issues raised by the public. Information feedback does not happen overnight, it is a continuous process. The public should be regularly consulted, and a full-time department should be established to give positive feedback to it. This continuous cycle can improve work efficiency.

\subsection{Park Construction Suggestions}

Exploring the development path with the characteristics of the Zhengzhou Shang Dynasty relic - the traditional management and operation model is government-led, which may become a heavy burden for the government. Efforts should be made to explore a development model suitable for the Zhengzhou Shang Dynasty city wall relic park, the cultural industry and tourism should be actively developed, and the popularity of the scenic spot should be vigorously publicized and increased. Not only can it increase local economic income, but it can also reduce the government's economic burden during park maintenance and construction. 
Improving the scientific management system and infrastructure construction-Promoting the transportation system with the Shang Dynasty relic as the landmark, promoting public transportation, and increasing social participation. Facility maintenance and hygienic issues need attention and improvement. The night lighting facilities of Shang Dynasty Park should be gradually improved to increase the vitality of the city wall park at night.

Improving overall design quality and physiological comfort- Design landscape elements reasonably. The style coordination area should be set up near the relic park, and buildings with low construction quality, such as illegal random construction should be demolished. Set up green barriers to isolate the adverse impact of the modern urban environment on the park landscape. The landscape should plant a variety of ornamental to increase species richness.

Improving the protection display forms and increasing humanistic elements - the rammed earth technology and the 3,000-year vicissitude history of the city wall itself are cultural resources with great historical value and need to be properly used. Rely on the city wall relic resources, increase cultural and historical elements, increase the number of cultural landscapes related to the history of the Shang Dynasty capital and the construction of the city walls, improve the overall cultural atmosphere of the park, and build the park into a heritage park with a distinctive theme. Regular large-scale cultural interactive activities should be carried out to enhance the historical atmosphere of the park.

\section{References}

1. N. Li, Q. Li, X. Zeng, J of Building Materials, 15(4), 562-564 (2012)

2. X. Zhu, S. Wu, Archit J, 5,42-44 (2002)

3. L. Chen, B. Yue, H.Zhao, J of Xi'an Uni of Archit \& Techn, 47(6), 899-904 (2015)

4. D. Zhao, B. Xu, J of Northeastern University (Natural Science) , 39(6), 776-780 (2018)

5. H. Lv, H. Zhao, G. Lin, Chinese Landscape Archit, 11, 58-61 (2016) 